\title{
Comparison of Two Citizen Scientist Methods for Collecting Pond Water Samples for Environmental DNA Studies
}

\author{
Andrew Buxton, Jim Groombridge and Richard Griffiths
}

\begin{abstract}
The use of environmental DNA (eDNA) for the survey of aquatic species offers a wide range of benefits over conventional surveys and has begun to be used by citizen scientists. One advantage of eDNA over conventional survey protocols is the comparative ease with which samples can be collected over a wide geographic area. However, eDNA collection protocols vary widely between different studies, promoting a need to identify an optimum method. Collection protocols include ethanol precipitation and various filtration methods including those that use electronic vacuum or peristaltic pumps, hand pumps, or syringes to capture eDNA on a membrane. We compare the effectiveness of two eDNA collection methods suitable for use by citizen scientists: Glass-microfiber syringe filtration and ethanol precipitation. Paired samples of water were analysed for Great Crested Newt (Triturus cristatus) DNA using (1) a laboratory tank experiment using different dilutions of water inoculated with newt DNA; and (2) by sampling naturally colonised ponds. Although syringe filters consistently yielded greater DNA extract concentrations in the tank experiments, this was not the case in samples collected from the field where no difference between the two methods was identified. Clearly, properties within the water-such as algae and particulate matter-can influence the amount of DNA captured by the two methods, so the sampling protocol of choice will depend on the design and goals of the study.
\end{abstract}

Keywords: environmental DNA; syringe filters; ethanol precipitation; laboratory tanks; pond; citizen science

\section{Introduction}

With threats to biodiversity increasing (Barnosky et al. 2011; Pimm et al. 1995), rapid biodiversity assessment and the ability to reliably detect species that are rare or have patchy distributions is imperative for effective evidence-based conservation actions to be implemented (Ficetola et al. 2008; Magurran 2004). Data generated by citizen science are widely used for species distribution assessments and other ecological research (Bonney et al. 2009; Van Strien, Van Swaay, and Termaat 2013). Various challenges exist in working with ecological citizen science data, however, most notably error and bias due to variation among observers (Dickinson, Zuckerberg, and Bonter 2010). Accuracy of visual based species identification may be as low as 60\% for non-experts (Austen et al. 2016).

Citizen science schemes for monitoring amphibians are active within the UK, for example the National Amphibian and Reptile Recording Scheme (NARRS) (Wilkinson and Arnell 2013). Such surveys, particularly those for the Great

University of Kent, GB

Corresponding author: Andrew Buxton

(andrews.buxton@btinternet.com)
Crested Newt (Triturus cristatus), require the use of multiple survey visits and multiple methods to achieve a reasonable probability of detection (Griffiths, Raper, and Brady 1996; Langton, Beckett, and Foster 2001; Wilkinson and Arnell 2013). Methods include a combination of torchlight visual searches of ponds at night, overnight bottle trapping, sweep netting to catch individuals, and searches of vegetation for eggs. Each of these methods requires a considerable amount of time at a pond; has health and safety implications for surveyors (for example working at night); can have variable reliability of detection influenced by environmental factors; and may require extensive training and licencing to ensure that the survey is carried out with minimum risk to target and non-target organisms (Langton, Beckett, and Foster 2001). Combining all four of these methods in a single survey visit yields a probability of detecting the presence of Great Crested Newts of between $0.41-0.68$. To improve confidence that a site is unoccupied to the 95\% level requires between 3-6 visits using traditional methods (Sewell, Beebee, and Griffiths 2010). As a result, a regional or landscape-wide survey programme can be logistically difficult, prohibitively expensive, and require multiple visits and skilled surveyors with taxonomic training (Biggs et al. 2015; Sewell, Beebee, and 
Griffiths 2010). The intensity of the survey methodologies and the number of visits required to achieve high levels of confidence in the results can lead to low retention of volunteers in surveys (Pers. comm. Dr John Wilkinson).

Given the issues with traditional amphibian survey methods, simple yet reliable survey methods that can be carried out by citizen scientists are in demand. One technique is environmental DNA (eDNA) surveillance, during which DNA is isolated from a sample of environmental material and used to identify the presence of a species or community of species (Jane et al. 2015). Since 2008, eDNA has become a widespread tool for detecting invasive aquatic species (Ficetola et al. 2008; Jerde et al. 2011; Wilson et al. 2014) and species of conservation importance (Biggs et al. 2015). Laboratory analysis based on DNA circumvents variation in species identification among surveyors and should reduce inaccuracies in datasets to which many individuals contribute.

Despite wide use by the research community, eDNA has had limited uptake within citizen science studies. Its utility for citizen scientists to detect Great Crested Newts has been demonstrated by the Freshwater Habitats Trust Pond Net scheme (Biggs et al. 2015; Freshwater Habitats Trust 2017) and the "Great Crested Newt Detectives" project of Amphibian and Reptile Conservation in Scotland (Minting 2016), both within the UK. The method has much wider applicability with citizen science based studies, however, allowing assessments of species distribution at scales that would make conventional or commercial surveys prohibitive (Biggs et al. 2015; Gibson et al. 2015). Collecting environmental samples for eDNA analysis requires little training and can be done quickly. Samples can be collected in the field at any time that suits citizen science participants, with water samples returned to a central location for shipment to a laboratory for analysis. DNA can then be isolated and identified using molecular techniques such as real-time quantitative PCR (qPCR) (Thomsen et al. 2012) or metabarcoding (Valentini et al. 2016).

eDNA sample collection requires a much shorter time at a pond than traditional methods, and is often conducted using only a single sample collected during one visit, resulting in detection probabilities much greater than those for a single visit using conventional methodologies (Buxton, Groombridge, and Griffiths 2018). The reduced number of visits required and lower intensity of sample collection increases the number of sites that a single volunteer can survey for a given effort and may increase volunteer retention, facilitating an increase in scale for a study as a whole, while increasing statistical rigor (Wilkinson and Arnell 2013). Additionally, surveys targeting eDNA lessen disturbance to the studied species by reducing the number of visits required to a pond, removing the need to disturb the structure of a pond with sweep netting and removing animal welfare concerns associated with trapping. eDNA also increases the accuracy of results by removing ambiguity arising from visual species identification. As such, eDNA offers a new tool for use by citizen science project designers for generating large, accurate species distribution data sets.

A variety of methods have been used for collecting aquatic environmental samples for DNA analysis, and when using eDNA, it is vital to choose sampling methodologies that are appropriate for the goals of the research. Most studies to date have focused on how best to detect a target species from samples rather than the reliability of the sample collection protocol itself (Deiner et al. 2015; Goldberg et al. 2016). The most popular protocols use one of two approaches. Firstly is precipitation in ethanol, where a sample of water is preserved within a large volume of absolute ethanol and a small volume of a salt (Biggs et al. 2015; Deiner et al. 2015; Eichmiller, Miller, and Sorensen 2016; Ficetola et al. 2008; Spens et al. 2016). Alternatively, a sample of water can be passed across a micropore membrane to concentrate and preserve DNA, however, the volume of water, membrane substrate, and membrane pore sizes used vary considerably between studies (Goldberg et al. 2016). A summary of methods used by different studies has been collated by Rees et al. (2014b). The different sample collection and extraction methodologies have advantages and disadvantages, but few studies have assessed how they perform against each other, or within different environments, i.e., in ponds, lakes, rivers, and the marine environment. Some studies have found that filtration recovers more DNA than ethanol precipitation (Deiner et al. 2015; Eichmiller, Miller, and Sorensen 2016; Spens et al. 2016), however, these studies focus on stream and lake environments and do not take into account environmental conditions unique to ponds.

Likewise, not all sampling protocols are suitable for citizen science initiatives (Biggs et al. 2015). For example, many filtration protocols require the transport of large volumes of unpreserved sample water, on ice, to a central location for filtration (Pilliod et al. 2013), while others use expensive electronic pumping equipment in the field (Pilliod et al. 2013). Neither approach is easily adopted by-nor practical forcitizen science studies, where volunteers may be expected to collect a small number of samples in a time frame fitted around other commitments. Due to the very low environmental concentrations of target DNA, it is imperative that eDNA sample collection and extraction methods recover the highest amount of DNA possible in a sample.

Here we assess two eDNA collection methods that would be applicable to a citizen science study for which a large number of surveyors each collect a small number of samples. We evaluated these methods for their suitability for citizen science because they do not require bulky, expensive, or electronic pumping equipment or the transport of large volumes of water, and the data-collection tools can be supplied as individual sealed kits for each sample. We tested the precipitation in ethanol method (Biggs et al. 2015) and the syringe filtration (Deiner et al. 2015) with glass microfiber syringe filtration method, aiming to identify whether eDNA extract concentrations varied between the two methods as they would be used in the field. We did this in both laboratory tanks and ponds, using water volumes applicable to the different methods. We targeted the Great Crested Newt, a semi-aquatic amphibian that has been widely used as a study species within eDNA research and citizen science (Biggs et al. 2014, 2015; Buxton et al. 2017; Buxton, Groombridge, and Griffiths 2017; Minting 2016; Rees et al. 2014a, 2017; Thomsen et al. 2012), and 
one for which commercial eDNA analysis has been pioneered (Natural England 2014).

\section{Methods \\ Field Samples}

Two eDNA collection methods, precipitation in ethanol (hereafter referred to as "ethanol precipitation"), and glassmicrofiber filtration using syringe filters (hereafter referred to as "filtration") were compared using water samples from a naturally colonised pond system. A network of eight small (600 L, $1 \mathrm{~m}$ by $2 \mathrm{~m}$ and up to $0.6 \mathrm{~m}$ deep) ponds used by Great Crested Newts, at the University of Kent, Canterbury Campus (UK), were utilised (Buxton et al. 2017). Sixty-one pairs of eDNA samples were collected from the eight ponds, by experienced researchers, using the ethanol precipitation and filtration methods between March and September 2015, covering the period when adults and larvae are in their aquatic phase.

Prior to field collection all equipment was sterilised in $10 \%$ bleach and thoroughly rinsed with water, sterilised in an autoclave or UV-Crosslinker, and then sealed prior to transport to the study site. Due to the small size of the ponds, each sample consisted of a single $1 \mathrm{~L}$ surface water sample from the pond centre. The order in which the two samples were taken was randomised to remove sampling bias. To prevent contamination, a fresh set of disposable gloves was used for each of the samples.

Sample collection followed the protocol outlined in Buxton et al. (2017). In brief, to collect the filtration samples, a sterilised $1 \mathrm{~L}$ water bottle was unsealed and rinsed with pond water prior to being filled. A disposable $100 \mathrm{~mL}$ syringe was used to pass the sample water across a Sterlitech Corporation ${ }^{\circledR}$ glass-microfiber syringe filter (0.7 $\mu \mathrm{m}$ pore size, $30 \mathrm{~mm}$ diameter), refilling the syringe until $1 \mathrm{~L}$ had been filtered or the 2 filter units had become blocked. Two syringes of air were then passed through each filter to reduce the amount of residual water in the sealed unit. Filters were sealed in plastic bags and transported to the laboratory. The maximum time between sample collection and reaching the laboratory was three hours, with samples then maintained at $-20^{\circ} \mathrm{C}$ until extraction.

Ethanol precipitation sample collection followed a protocol outlined in Buxton et al. (2017), originally from Biggs et al. (2015). In brief, six, $50 \mathrm{~mL}$ centrifuge tubes, each containing $33 \mathrm{~mL}$ of absolute ethanol and $1.5 \mathrm{~mL}$ of $3 \mathrm{M}$ sodium acetate solution were filled to the $50 \mathrm{~mL}$ gradation with sample water using a disposable plastic pipette. This volume equates to approximately $15 \mathrm{~mL}$ of sample being placed into each of the 6 sample tubes and a total sample volume of approximately $90 \mathrm{~mL}$. The lid to each tube was sealed, and the tube contents mixed by inversion. All six sample tubes were then placed in a sealable bag for transport to the laboratory. The maximum time between sample collection and reaching the laboratory was three hours, with samples then maintained at $-20^{\circ} \mathrm{C}$ until extraction.

\section{Serial Dilution of Tank Water}

A laboratory experiment was carried out using Great Crested Newts under controlled conditions. Plastic boxes, dimensions $490 \mathrm{~mm} \times 360 \mathrm{~mm} \times 240 \mathrm{~mm}$ deep, were set up in a temperature controlled room $\left(18^{\circ} \mathrm{C} \pm 2{ }^{\circ} \mathrm{C}\right)$, containing $10 \mathrm{~L}$ of tap water. The water was allowed to stand for a minimum of 24 hours to allow the water to naturally dechlorinate. Great Crested Newts were collected using the standard bottle trapping method (Langton, Beckett, and Foster 2001) from a pond within the campus of the University of Kent and taken into captivity under licence from Natural England (Licence number 2015-10937-SCI$\mathrm{SCI}$. The newts were allowed to acclimatise to the temperature of the room in tanks containing water from their original pond before one newt was introduced to each experimental tank. The individuals were left in the study tanks for 24 hours before being removed and released into their original pond. Five replicate tanks were used between the 28th and 29th of April 2015, and an additional three replicates between the 14th and the 15th of May 2015.

Prior to sample collection, all equipment was sterilised in $10 \%$ bleach and thoroughly rinsed with water, sterilised in an autoclave or UV-Crosslinker, and then sealed. Once the individuals had been removed from the tanks, a 1 in 2 dilution series was performed on the tank water to create samples at $100 \%, 50 \%, 25 \%, 12.5 \%, 6.25 \%$ and $3.125 \%$ of the starting concentration of the tank water. Dilution was undertaken with tap water, making $1 \mathrm{~L}$ of sample water at each dilution for each tank. The dilutions were made using the lowest concentration first in order to prevent contamination between levels. An ethanol precipitation eDNA sample of $0.09 \mathrm{~L}$ was initially taken, with the remainder of the water, totalling $0.91 \mathrm{~L}$, then passed through two Sterlitech Corporation ${ }^{\circledR}$ glass-microfiber syringe filters ( $0.7 \mu \mathrm{m}$ pore size, $30 \mathrm{~mm}$ diameter) in equal proportions, following the protocols described above. In total 48 pairs of samples were collected. Samples were then stored at $-20^{\circ} \mathrm{C}$ until DNA extraction.

\section{Extraction Protocols}

DNA extractions were conducted following the protocol outlined in Buxton et al. (2017). In brief, all extractions were undertaken in a UV sterilisable work station, with dedicated equipment, and were based on the Qiagen $\AA$ DNeasy ${ }^{\circledR}$ Blood \& Tissue kit with amended protocols as outlined. Periodic extraction blanks for both methods were undertaken through the laboratory phase of the project to check for equipment contamination.

Syringe filtration samples were extracted in a fume hood sterilised with a $10 \%$ bleach solution and UV-light, the filter paper was removed from the sealed syringe filter holder using sterilised wire cutters and sterilised forceps. Once removed, the filters were cut into strips approximately $3 \mathrm{~mm}$ in width, with each filter placed into a separate $1.5 \mathrm{~mL}$ microcentrifuge tube. Thus, in the digestion step each sample consisted of two microcentrifuge tubes, one for each of the two filters. $675 \mu \mathrm{L}$ of the ATL buffer from the DNeasy ${ }^{\circledR}$ Blood \& Tissue kit (Qiagen ${ }^{\circledR}$ ) was added to each tube; it was then vortexed for 15 seconds to mix before $20 \mu \mathrm{L}$ of Pro K was added and again vortexed. The samples were then incubated on a rotating block, for 3 hours at $56^{\circ} \mathrm{C}$, or overnight at $37^{\circ} \mathrm{C}$. Following incubation, the two digestion reactions for a sample were 
combined in a fresh microcentrifuge tube. DNA extraction continued as per the DNeasy® Blood and Tissue kit manufacturers' protocol, eluting into $200 \mu \mathrm{L}$ of the elution buffer.

eDNA extraction from ethanol precipitation samples was undertaken using a modified protocol from Biggs et al. (2014). The six centrifuge tubes were centrifuged at $10,020 \mathrm{~g}$, (8500 rpm) for 35 minutes and the supernatant discarded. The remainder of the extraction protocol followed the modified Qiagen ${ }^{\circledR}$ DNeasy ${ }^{\circledR}$ blood and tissue kit protocol, from Biggs et al. (2014).

\section{qPCR analysis}

Following extraction, samples were stored at $-20^{\circ} \mathrm{C}$ until real-time qPCR could be undertaken. qPCR plate set up was conducted in a separate dedicated laboratory, also within a separate UV-sterilisable work station. qPCR was performed using qPCR primers and a hydrolysis probe and assay designed by Thomsen et al. (2012) and validated by Biggs et al. (2014, 2015), using TaqMan ${ }^{\circledR}$ Environmental Master Mix 2.0 (Applied Biosystems ${ }^{\circledR}$ ). Samples were run on a BIO-RAD ${ }^{\circledR}$ CFX Connect Real-Time PCR detection system, under thermal cycling conditions from Biggs et al. (2014, 2015). Eight qPCR replicates were performed on each sample (Ficetola et al. 2014). qPCR standards were created from a serial dilution of a Great Crested Newt tissue extract, quantified using a Qubit ${ }^{\circledR} 2.0$ fluorometer (Life Technologies ${ }^{\circledR}$ ) with the double stranded DNA high sensitivity kit following manufacturers' instructions. Three standards were used in each assay, acting as posi- tive controls and to allow quantification using a standard curve. Negative qPCR controls were also included.

\section{Analysis}

All statistics were undertaken using $\mathrm{R}$ version 3.1.3. ( $\mathrm{R}$ Development Core Team 2016); the tests used are indicated within the results section. Median values were used in the analysis rather than arithmetic mean to prevent outlying qPCR replicates from affecting the extract concentration. Linear regression was conducted comparing the dilution level and extract concentration. An analysis of covariance (ANCOVA) was then performed on the linear regression models to compare the effect of collection method on the DNA extract concentration. Wilcoxon-Pratt signed rank tests were then used to compare filter and ethanol precipitation samples to ascertain whether there was a statistically significant difference in extract concentration between the two methods. This analysis was undertaken independently for paired samples collected from the laboratory tanks and samples collected from ponds.

\section{Results}

\section{Samples from naturally colonised ponds}

All positive field samples were found to be above the limit of quantification for this study, the minimum concentration that can be reliably quantified by the qPCR assay (Buxton et al. 2017). There was no difference in extract concentration from filters and ethanol precipitation paired samples collected from ponds (Wilcoxon-Pratt signed-rank test $\mathrm{z}=-1.03 ; \mathrm{p}=0.30$; Figure 1).

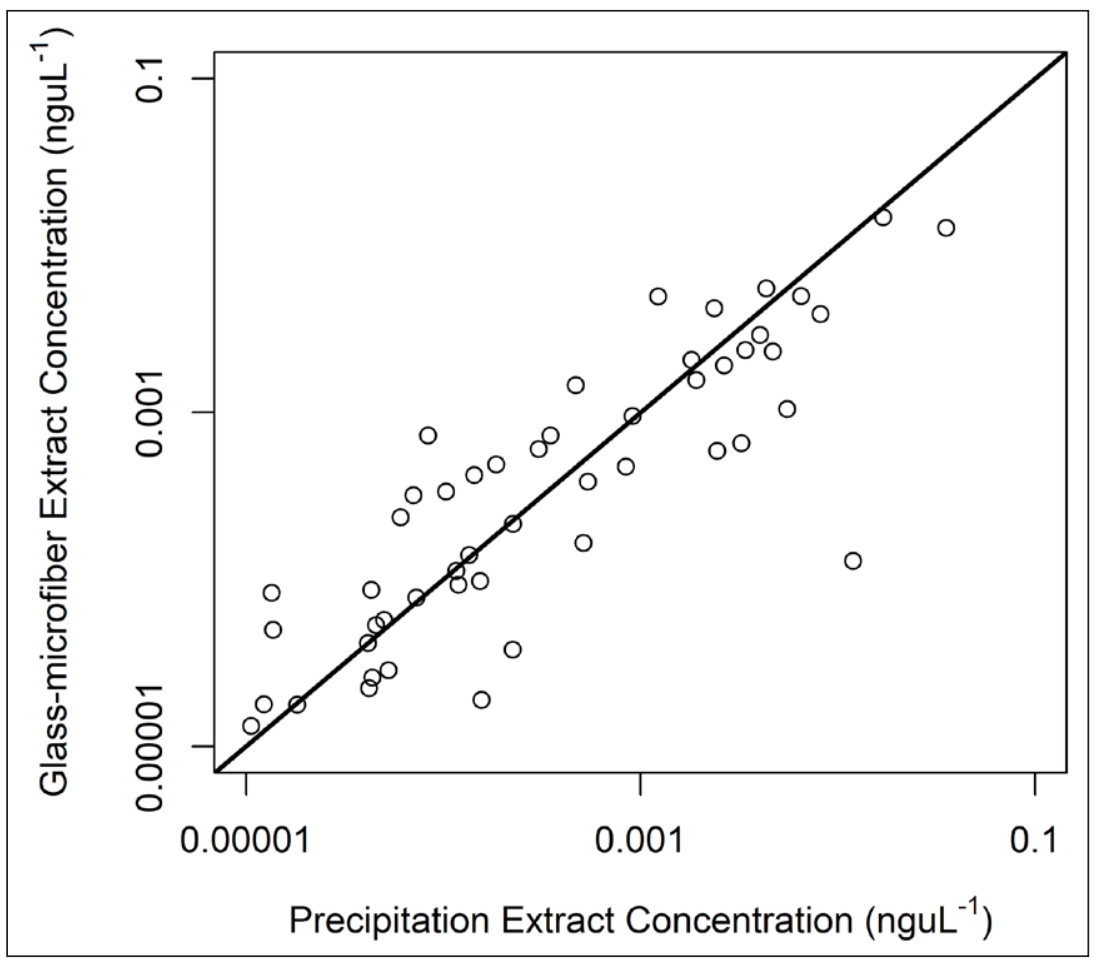

Figure 1: Paired eDNA samples collected from natural ponds. The black line indicates the point at which the two extract concentrations have equal DNA concentration. Sample pairs with greater extract concentration from the glass-microfiber filter collection method appear above the line and sample pairs with greater extract concentration from the precipitation method appear below the line. Due to logarithmic scale where one or both of a pair have a concentration of zero, no result is shown. 
We analysed the eDNA score (proportion of positive qPCR replicates) for the two collection methods for all 61 paired eDNA samples. Again we found no significant difference between the sample collection methods (Wilcoxon-Pratt signed-rank test $\mathrm{z}=-1.0 ; \mathrm{p}=0.319$ ).

\section{Experimental Serial Dilution}

All samples from the experimental serial dilution fell above the qPCR minimum concentration for reliable quantification (limit of quantification) (Buxton et al. 2017). Regression analysis of the level of dilution on the final extract concentration was highly significant for both the ethanol precipitation $(\mathrm{t}=5.0$; $\mathrm{df}=46$; $\mathrm{p}<0.0001)$ and filter $(\mathrm{t}=6.3$; $\mathrm{df}=46 ; \mathrm{p}<0.0001)$ collection methods. A significant interaction (ANCOVA: $\mathrm{F}=33.3 ; \mathrm{df}=1,93 ; \mathrm{p}<0.0001$ ) was found between the collection method and the sample dilution level. In addition to the significant difference in slope between the two eDNA collection methods, the intercept was also found to be different (precipitation $=2.541 \times 10^{-5} \mathrm{ngul}^{-1}$; glass-microfiber filter $=0.003892 \mathrm{ngul}^{-1}$ ). This indicates that the effect of initial sample concentration on the final extract concentration depends on the collection method used (Figure 2).

For each of the paired samples at all dilution levels, the filtered samples yielded a greater extract concentration than the corresponding sample collected using the ethanol precipitation method (Figure 3). This result was highly significant (Wilcoxon-Pratt signed-rank test: $\mathrm{z}=6.03, \mathrm{p}<0.0001)$.

\section{Discussion}

In experimental tanks where water contained no organic or particulate matter, filtration of $0.91 \mathrm{~L}$ of sample water using $0.7 \mu \mathrm{m}$ glass-microfiber syringe filters recovered larger amounts of eDNA than ethanol precipitation with a sample volume of $0.09 \mathrm{~L}$ across the range of sample water concentrations tested. However, when assessed in the field with real pond water, no significant difference between the collection methods was observed.

We compared two methodologies considered to be suitable for use within widespread citizen science projects, where provision of equipment such as peristaltic pumps would not be logistically or financially viable (Biggs et al. 2015). However, we recognise that other filtration methodologies are available that require the use of pumping equipment, which may allow for increased eDNA capture rates (Minamoto et al. 2016; Spens et al. 2016).

The concentrations of target DNA in the extracts from the laboratory tanks were within or above the range of that observed in the natural ponds. Our results from the laboratory tanks support previous work on lake water, which showed that filtration recovers greater amounts of total and target eDNA than the ethanol precipitation method (Spens et al. 2016). However, Spens et al. (2016) used different filters and sampling volumes from the present study. Increased sample volumes used in the filtration method are likely to have been responsible for the greater concentrations of eDNA recovered, when compared with the ethanol precipitation method, in the tank experiment.

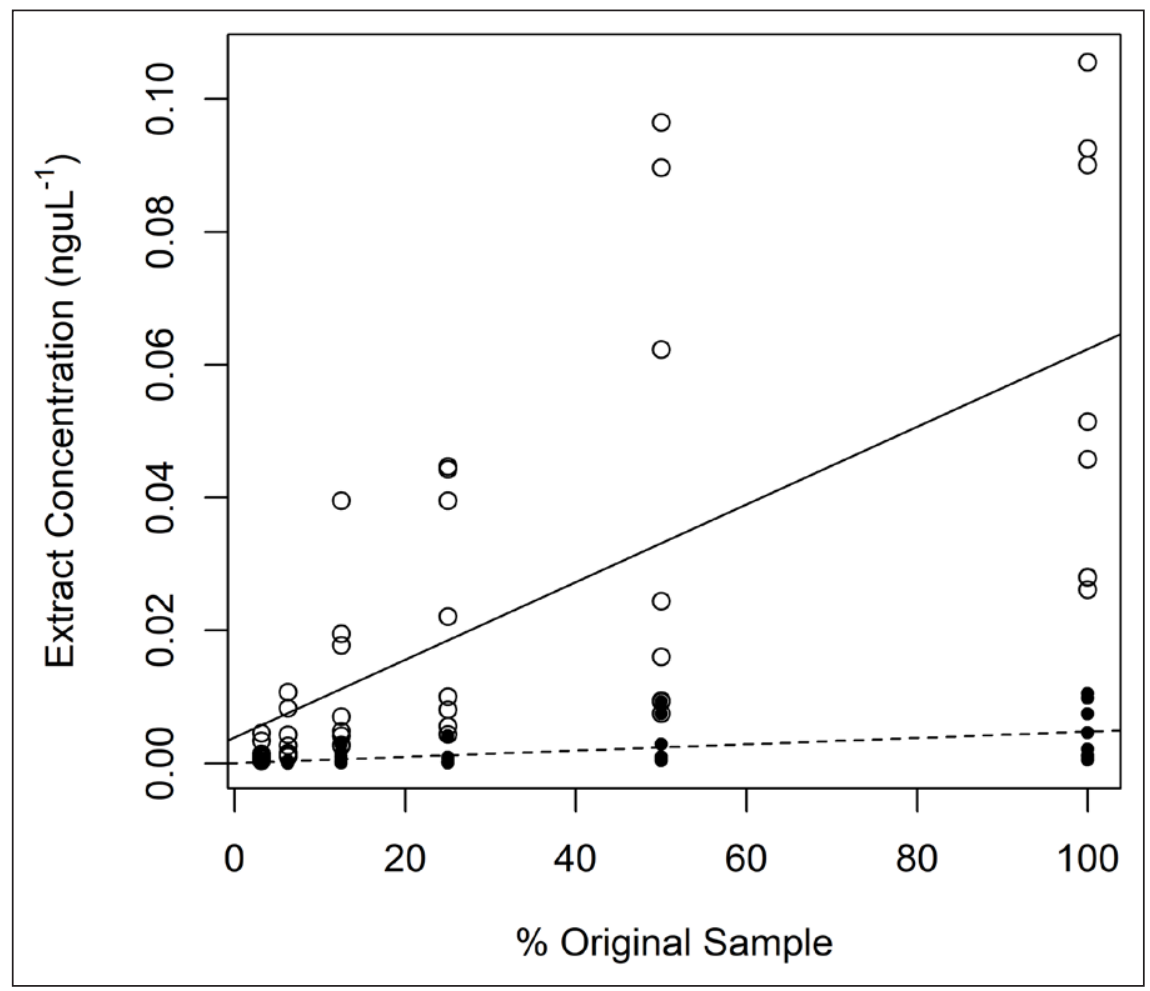

Figure 2: Relationship between DNA extract concentration and the level of dilution. Each point represents the median qPCR concentration value for an eDNA sample for two collection methods at the different dilution levels. Open circles represent samples collected via filtration, closed circles represent samples collected via ethanol precipitation. 


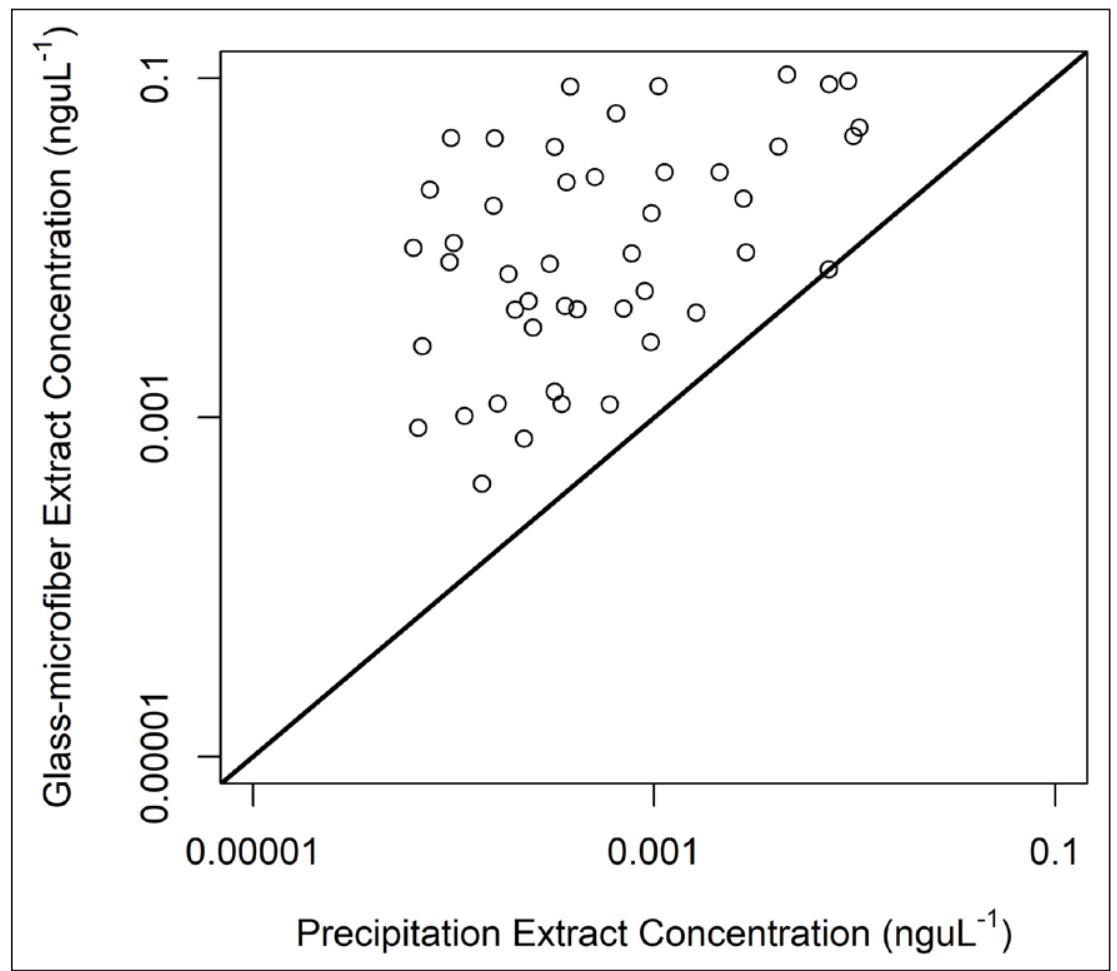

Figure 3: Paired eDNA samples collected from serial dilution of tank water. The black line indicates the point at which the two extract concentrations would have equal DNA concentration. Sample pairs with greater extract concentration from the glass-microfiber filter collection method appear above the line and sample pairs with greater extract concentration from the precipitation collection method appear below the line. Note the logarithmic scale for clarity.

The difference in extract concentrations between the two sampling methods observed in the laboratory tanks was not repeated in the field samples. This result may reflect the composition of pond water compared with tap water. When processing natural pond water, filters may become blocked by suspended solids and algae that were not in the samples from laboratory tanks. We found that that $0.91 \mathrm{~L}$ of water from laboratory tanks could easily be passed through two filters. In contrast, in some field samples it was not possible to pass $500 \mathrm{~mL}$ of pond water through two glass-microfiber filters disks. The lower water volume is likely to reduce the amount of eDNA captured and therefore the quantity available for extraction. In contrast, during the initial precipitation and centrifugation step with the ethanol precipitation samples, suspended solids and algae precipitated out of solution with the eDNA collecting as a pellet on the side of the tube. This additional material may have assisted in securing the eDNA in the pellet, preventing it being discarded with the supernatant and increasing the amount of DNA within the extract.

Pond water can differ from water found in rivers, lakes, or the marine environment. Pond water is more stagnant, allowing the build-up of algae and suspended solids to a greater extent than lotic water or large lakes where stratification and wind action allow for water movement. The results from our field experiment do not fully support the conclusions of Spens et al. (2016) or Deiner et al. (2015), both of whom conclude that filtration outperforms precipitation. In our experiment we observed no difference between the sampling methods when they are applied to pond water. However, these two studies utilised lake and river water respectively and so may not have faced the same limitations found with ponds.

Deiner et al. (2015) show that different combinations of sampling and extraction protocols are appropriate when targeting different taxa, and conclude that it is imperative to pick the combination best suited to the specific study, advice also advocated by Minamoto et al. (2016). Our results suggest that this approach should be extended to environment type as well as to taxon, given that the difference in recovery between the sample types, which we observed in tank experiments, disappears with pond water.

Within the laboratory tank experiment there was a significant relationship between the level of dilution and eDNA extract concentration, with more diluted samples showing a reduced extract concentration. However, some samples exhibited greater extract concentration than more heavily diluted samples collected from the same tank. Although this may result from sampling error, it was apparent with both collection methods, but was more prominent in ethanol precipitation samples. This finding suggests that even though concentration of eDNA extracts are related to the amount of DNA within the water sampled, extraction efficiency between samples may not be consistent, or the amount of eDNA within a sample may be heavily influenced by the form that the eDNA takes (extracellular, single cells, or aggregations of cells). Assuming that the majority of eDNA collected is intracellular (Deiner et al. 
2015; Rees et al. 2014b), concentration may be influenced by aggregations of cells within samples, with larger water volumes used with the filtration samples helping to mitigate for this.

To detect statistically meaningful changes in pond occupancy by amphibians on a regional or national scale using traditional visual based survey methods, the number of sites needed to be visited and the survey effort required may be prohibitive (Biggs et al. 2014; Wilkinson and Arnell 2013). This would be the same for citizen scientists or professional surveyors. New survey methods, such as the targeting of eDNA, require fewer visits to a pond, less time on site, and more sociable working hours. This may allow surveys to be undertaken on a larger scale, thereby improving estimates of occupancy and population change, which have been goals of citizen science led national monitoring projects such as the Amphibian and Reptile Conservations Trust (ARC) NARRS project (Wilkinson and Arnell 2013). However, there is a financial cost associated with processing eDNA samples, and the laboratory analysis would need to be budgeted from the outset. The use of the eDNA technique by citizen scientists within national or regional distribution assessment projects has been demonstrated within the ARC Great Crested Newt Detectives project in Scotland (Minting 2016) and the Freshwater Habitats Trust PondNet project (Biggs et al. 2015). These projects are managed centrally by nature conservation charities partnering with a commercial laboratory. The nature conservation charities draw on their network of volunteers and advise on identification of locations to collect samples, obtaining access permissions as well as running training on the use of eDNA kits. The laboratory partner provides eDNA sampling kits to the volunteer surveyors and undertakes the genetic analysis, returning the results to the charity to compile the data. It is imperative that the volunteer surveyor's receive prompt feedback on the samples they collect, to maintain the link between surveyors and results, maintaining participant engagement that could be lost through the lack of interaction with the target species itself. The availability of eDNA survey methods for projects utilizing samples collected by citizen scientists has the potential to be utilised for a wide range of taxa of conservation concern.

Citizen scientists clearly have options for eDNA sample collection. However, the collection of filtered samples from natural ponds with filtration was challenging, as filters can easily become blocked, and this may not lend itself to participant engagement and retention. Citizen scientists are likely to vary in the level of perseverance when trying to pass water across a filter. This may cause differences in the amount of water collected between individuals under the same conditions, impacting the consistency of the results and reducing the efficiency of the filtration method. Although filtration outperformed ethanol precipitation under experimental conditions, citizen scientists would be sampling natural ponds. Given that no difference in performance was observed between the methodologies in the field, either methodology would seem to be equally applicable under the conditions encountered here. However, different methods may recover different amounts of eDNA in different situations. We recommend that pilot studies be undertaken to identify the most appropriate method for individual studies, with decisions on the most appropriate method taking into account practical considerations relating to the two methods, and the specific study needs.

\section{Acknowledgements}

We would like to thank Joseph Jones and Nurulhuda Zakaria for assisting with the field work and sample collection. We would also like to thank Jim Foster and Dr John Wilkinson from Amphibian and Reptile Conservation, and Dr Jeremy Biggs from Freshwater Habitats Trust, for their advice. We also like thank the University of Kent for providing top-up funds to the self-funded PhD project. Finally, we would like to thank the editor and two anonymous reviewers for their comments on an earlier version of the manuscript.

\section{Competing Interests}

The authors have no competing interests to declare.

\section{References}

Austen, GE, Bindemann, M, Griffiths, RA and Roberts, DL. 2016. Species identification by experts and non-experts: Comparing images from field guides. Scientific Reports, 6: 33634. DOI: https://doi. org/10.1038/srep33634

Barnosky, AD, Matzke, N, Tomiya, S, Wogan, GOU, Swartz, B, Quental, TB, Marshall, C, McGuire, JL, Lindsey, EL, Maguire, KC, Mersey, B and Ferrer, EA. 2011. Has the Earth's sixth mass extinction already arrived? Nature, 471: 51-57. DOI: https://doi. org/10.1038/nature09678

Biggs, J, Ewald, N, Valentini, A, Gaboriaud, C, Dejean, T, Griffiths, R, Foster, J, Wilkinson, J, Arnell, A, Brotherton, P, Williams, P and Dunn, F. 2015. Using eDNA to develop a national citizen sciencebased monitoring programme for the great crested newt (Triturus cristatus). Biological Conservation, 183: 19-28. DOI: https://doi.org/10.1016/j.biocon.2014.11.029

Biggs, J, Ewald, N, Valentini, A, Gaboriaud, C, Griffiths, R, Foster, J, Wilkinson, J, Arnett, A, Williams, P and Dunn, F. 2014. Analytical and methodological development for improved surveillance of the great crested newt. Defra Project WC1067.

Bonney, R, Cooper, CB, Dickinson, J, Kelling, S, Phillips, T, Rosenberg, KV and Shirk, J. 2009. Citizen science: A developing tool for expanding science knowledge and scientific literacy. BioScience, 59: 977-984. DOI: https://doi.org/10.1525/bio.2009.59.11.9

Buxton, AS, Groombridge, JJ and Griffiths, RA. 2017. Is the detection of aquatic environmental DNA influenced by substrate type? PLOS ONE, 12: e0183371. DOI: https://doi.org/10.1371/journal.pone.0183371

Buxton, AS, Groombridge, JJ and Griffiths, RA. 2018. Seasonal variation in environmental DNA detection in sediment and water samples. PLOS ONE, 13: e0191737. DOI: https://doi.org/10.1371/journal.pone.0191737 
Buxton, AS, Groombridge, JJ, Zakaria, NB and Griffiths, RA. 2017. Seasonal variation in environmental DNA in relation to population size and environmental factors. Scientific Reports, 7: 46294. DOI: https://doi.org/10.1038/srep46294

Deiner, K, Walser, JC, Mächler, E and Altermatt, F. 2015. Choice of capture and extraction methods affect detection of freshwater biodiversity from environmental DNA. Biological Conservation, 183: 53-63. DOI: https://doi.org/10.1016/j.biocon.2014.11.018

Dickinson, JL, Zuckerberg, B and Bonter, DN. 2010. Citizen science as an ecological research tool: Challenges and benefits. Annual Review of Ecology, Evolution, and Systematics, 41: 149-172. DOI: https:// doi.org/10.1146/annurev-ecolsys-102209-144636

Eichmiller, JJ, Miller, LM and Sorensen, PW. 2016. Optimizing techniques to capture and extract environmental DNA for detection and quantification of fish. Molecular Ecology Resources, 16: 56-68. DOI: https:// doi.org/10.1111/1755-0998.12421

Ficetola, GFF, Cagnetta, M, Padoa-Schioppa, E, Quas, A, Razzetti, E, Sindaco, R and Bonardi, A. 2014. Sampling bias inverts ecogeographical relationships in island reptiles. Global Ecology and Biogeography, 23: 1303-1313. DOI: https://doi.org/10.1111/geb.12201

Ficetola, GFF, Miaud, C, Pompanon, F and Taberlet, P. 2008. Species detection using environmental DNA from water samples. Biology Letters, 4: 423-425. DOI: https://doi.org/10.1098/rsbl.2008.0118

Freshwater Habitats Trust. 2017. eDNA great crested newt survey data - 2016 eDNA results. 2017. Available at: https://freshwaterhabitats.org.uk/edna-greatcrested-newt-survey-data/ [Last accessed 22 November 2017].

Gibson, JF, Shokralla, S, Curry, C, Baird, DJ, Monk, WA, King, I and Hajibabaei, M. 2015. Large-scale biomonitoring of remote and threatened ecosystems via high-throughput sequencing. PLOS ONE, 10: e0138432. DOI: https://doi.org/10.1371/journal. pone.0138432

Goldberg, CS, Turner, CR, Deiner, K, Klymus, KE, Thomsen, PF, Murphy, MA, Spear, SF, McKee, A, Oyler-McCance, SJ, Cornman, RS, Laramie, MB, Mahon, AR, Lance, RF, Pilliod, DS, Strickler, KM, Waits, LP, Fremier, AK, Takahara, T, Herder, JE, Taberlet, P and Gilbert, M. 2016. Critical considerations for the application of environmental DNA methods to detect aquatic species. Methods in Ecology and Evolution, 7: 1299-1307. DOI: https://doi. org/10.1111/2041-210X.12595

Griffiths, RA, Raper, SJ and Brady, L. 1996. Evaluation of a standard method for surveying common frogs (Rana temporaria) and newts (Triturus cristatus, T. helveticus and T. vulgaris). JNCC Report No. 259.

Jane, SF, Wilcox, TM, Mckelvey, KS, Young, MK, Schwartz, MK, Lowe, WH, Letcher, BH and Whiteley, AR. 2015. Distance, flow and PCR inhibition: eDNA dynamics in two headwater streams. Molecular Ecology Resources, 15: 216-227. DOI: https://doi. org/10.1111/1755-0998.12285
Jerde, CL, Mahon, AR, Chadderton, WL and Lodge, DM. 2011. 'Sight-unseen' detection of rare aquatic species using environmental DNA. Conservation Letters, 4: 150-157. DOI: https://doi.org/10.1111/ j.1755-263X.2010.00158.x

Langton, TET, Beckett, CLC and Foster, JJP. 2001. Great crested newt conservation handbook. Halesworth: Froglife.

Magurran, A. 2004. Measuring biological diversity. Oxford, UK: Blackwell Science Ltd. DOI: https://doi. org/10.2989/16085910409503825

Minamoto, T, Naka, T, Moji, K and Maruyama, A. 2016. Techniques for the practical collection of environmental DNA: Filter selection, preservation, and extraction. Limnology, 17: 23-32. DOI: https://doi.org/10.1007/ s10201-015-0457-4

Minting, P. 2016. Greatcrested newt detectives. Bornmouth, UK: Amphibian and Reptile Conservation.

Natural England. 2014. Environmental DNA (eDNA) detects the presence of great crested newts in water. 2014. Available at: http://webarchive.nationalarchives. gov.uk/20140605105717/http://www.naturalengland.org.uk/ourwork/regulation/wildlife/gcn-eDNAfeature.aspx [Last accessed 12 November 2014].

Pilliod, DS, Goldberg, CS, Arkle, RS, Waits, LP and Richardson, J. 2013. Estimating occupancy and abundance of stream amphibians using environmental DNA from filtered water samples. Canadian Journal of Fisheries and Aquatic Sciences, 70: 1123-1130. DOI: https://doi.org/10.1139/cjfas-2013-0047

Pimm, SL, Russell, GJ, Gittleman, JL and Brooks, TM. 1995. The future of biodiversity. Science, 269: 347-350. DOI: https://doi.org/10.1126/science.269.5222.347

R Development Core Team. 2016. R: language and environment for statistical computing.

Rees, HC, Baker, CA, Gardner, DS, Maddison, BC and Gough, KC. 2017. The detection of great crested newts year round via environmental DNA analysis. BMC Research Notes, 10: 327. DOI: https://doi.org/10.1186/ s13104-017-2657-y

Rees, HC, Bishop, K, Middleditch, DJ, Patmore, JRM, Maddison, BC and Gough, KC. 2014a. The application of eDNA for monitoring of the great crested newt in the UK. Ecology and Evolution, 4: 4023-4032. DOI: https://doi.org/10.1002/ece3.1272

Rees, HC, Maddison, BC, Middleditch, DJ, Patmore, JRM and Gough, KC. 2014b. The detection of aquatic animal species using environmental DNA - a review of eDNA as a survey tool in ecology. Journal of Applied Ecology, 51: 1450-1459. DOI: https://doi. org/10.1111/1365-2664.12306

Sewell, D, Beebee, TJC and Griffiths, RA. 2010. Optimising biodiversity assessments by volunteers: The application of occupancy modelling to large-scale amphibian surveys. Biological Conservation, 143: 2102-2110. DOI: https://doi.org/10.1016/j.biocon.2010.05.019

Spens, J, Evans, AR, Halfmaerten, D, Knudsen, SW, Sengupta, ME, Mak, SST, Sigsgaard, EE and Hellström, M. 2016. Comparison of capture and 
storage methods for aqueous macrobial eDNA using an optimized extraction protocol: Advantage of enclosed filter. Methods in Ecology and Evolution, 8: 635-645. DOI: https://doi.org/10.1111/2041-210X.12683

Thomsen, PF, Kielgast, J, Iversen, L, Wiuf, C, Rasmussen, M, Gilbert, MTP, Orlando, L and Willerslev, E. 2012. Monitoring endangered freshwater biodiversity using environmental DNA. Molecular Ecology, 21: 2565-2573. DOI: https://doi. org/10.1111/j.1365-294X.2011.05418.x

Valentini, A, Taberlet, P, Miaud, C, Civade, R, Herder, J, Thomsen, PF, Bellemain, E, Besnard, A, Coissac, E, Boyer, F, Gaboriaud, C, Jean, P, Poulet, N, Roset, N, Copp, GH, Geniez, P, Pont, D, Argillier, C, Baudoin, JM, Peroux, T, Crivelli, AJ, Olivier, A, Acqueberge, M, Le Brun, M, Møller, PR, Willerslev, E and Dejean, T. 2016. Next-generation monitoring of aquatic biodiversity using environmental DNA metabarcoding. Molecular Ecology, 25: 929-942. DOI: https://doi. org/10.1111/mec.13428

Van Strien, AJ, Van Swaay, CAM and Termaat, T. 2013. Opportunistic citizen science data of animal species produce reliable estimates of distribution trends if analysed with occupancy models. Journal of Applied Ecology, 50: 1450-1458. DOI: https://doi. org/10.1111/1365-2664.12158

Wilkinson, JW and Arnell, AP. 2013. NARRS report 2007-2012. ARC Research Report 13/01.

Wilson, C, Wright, E, Bronnenhuber, J, Macdonald, F, Belore, M and Locke, B. 2014. Tracking ghosts: Combined electrofishing and environmental DNA surveillance efforts for Asian carps in Ontario waters of Lake Erie. Management of Biological Invasions, 5: 225231. DOI: https://doi.org/10.3391/mbi.2014.5.3.05

\footnotetext{
How to cite this article: Buxton, A, Groombridge, J and Griffiths, R. 2018. Comparison of Two Citizen Scientist Methods for Collecting Pond Water Samples for Environmental DNA Studies. Citizen Science: Theory and Practice, 3(2): 2, pp. 1-9, DOI: https:// doi.org/10.5334/cstp.151

Submitted: 06 February 2018 Accepted: 31 May 2018 Published: 21 August 2018

Copyright: (c) 2018 The Author(s). This is an open-access article distributed under the terms of the Creative Commons Attribution 4.0 International License (CC-BY 4.0), which permits unrestricted use, distribution, and reproduction in any medium, provided the original author and source are credited. See https://creativecommons.org/licenses/by/4.0/.
} 